\title{
Can Surgeons Use Parathyroid Hormone Levels as Predictive Value in Parathyroid Adenomas?
}

\author{
Merve Tokocin ${ }^{1}$, Talar Vartanoglu Aktokmakyan ${ }^{1 *}$, Ahmet Guray Durmaz ${ }^{1}$, Onur Tokocin ${ }^{2}$, \\ Huseyin Bilge ${ }^{3}$ and Erkan Yavuz ${ }^{1}$ \\ ${ }^{1}$ Department of General Surgery, Istanbul Bagcilar Training and Research Hospital, Turkey \\ ${ }^{2}$ Department of Emergency, Kagithane State Hospital, Istanbul, Turkey \\ ${ }^{3}$ Department of General Surgery, Dicle University, Faculty of Medicine, Turkey
}

\begin{abstract}
Aim: Previous studies using different methods for PTH measurement have found a mild to moderate correlation between iPTH and gland weight. The aim of this study was to describe the relationship between parathyroid hormone and parathyroid adenoma volume, in patients with parathyroid adenomas as predictive value.
\end{abstract}

Material and Methods: The multicenteric study was prepared by retrospectively collecting data from 244 patients with parathyroid adenoma who underwent parathyroidectomy and followed up between 2010 and 2020 .

Results: Two hundred forty and four (female/male $=203 / 41)$ patients with a mean age of 51.41 [min-max: 17 to 88 ] years. The mean iPTH concentrations preoperatively were $584.27 \mathrm{ng} / \mathrm{L}$ [minmax: 18.9 to $5011 \mathrm{ng} / \mathrm{L}$ ]. The mean diameter of adenoma of patients was $2,865 \mathrm{~mm}^{3}$ [min-max: 0.119 to $42.3 \mathrm{~mm}^{3}$ ]. After parathyroidectomy, PTH values were reevaluated and found as $47.2 \mathrm{ng} / \mathrm{L}$ [minmax: 0.2 to $903 \mathrm{ng} / \mathrm{L}$ ]. In the patients with large parathyroid adenoma volume, preoperative PTH hormone values were statistically significantly higher $(\mathrm{p}=0.001)$.

\section{OPEN ACCESS}

${ }^{*}$ Correspondence:

Talar Vartanoglu Aktokmakyan,

Department of General Surgery,

Istanbul Bagcilar Training and Research

Hospital, Turkey,

E-mail: talarim@gmail.com

Received Date: 30 Mar 2021

Accepted Date: 12 Apr 2021

Published Date: 16 Apr 2021

Citation:

Tokocin M, Aktokmakyan TV, Durmaz

AG, Tokocin O, Bilge H, Yavuz E.

Can Surgeons Use Parathyroid Hormone Levels as Predictive Value

in Parathyroid Adenomas?. Am J Otolaryngol Head Neck Surg. 2021;

4(3): 1128.

Copyright $\odot 2021$ Talar Vartanoglu Aktokmakyan. This is an open access article distributed under the Creative Commons Attribution License, which permits unrestricted use, distribution,

and reproduction in any medium, provided the original work is properly

cited.
Conclusion: Our current study found a positive association between baseline i PTH levels and adenoma weight. These results suggest that serum iPTH level may be useful in predicting parathyroid adenoma volume.

Keywords: Parathyroid adenoma; Parathyroid hormone; Parathyroidectomy

\section{Introduction}

Primary Hyperparathyroidism (PHPT) has been becoming a more recognized endocrine disease with the development of multichannel chemistry screening tests. PHPT is characterized by elevated plasma calcium levels with elevated or inappropriately normal serum concentration of intact Parathyroid Hormone (iPTH). The average annual incidence of Primary Hyperparathyroidism (PHPT) is 51 per 100,000 population [1]. Most cases ( $85 \%$ to $87 \%$ ) are caused by a solitary Parathyroid Adenoma (PTA) [2]. Detection and excision of all enlarged parathyroid tissue in the first surgery is the main goal of operative treatment in PHPT, due to the lower success rate and the significant increase in mortality and morbidity of the second exploration. Therefore, the ability to estimate the size of a parathyroid adenoma and determine its approximate location can greatly aid the surgeon before the operation [3]. Although there is a wide variety of endocrinological and imaging studies' including ultrasonography, intraoperative PTH assays, scintigraphy, Magnetic Resonance Imaging (MRI), and Computed Tomography (CT), a unique study has not shown that parathyroid adenomas are precisely defined in all patients. Previous studies using different methods for PTH measurement have found a mild to moderate correlation between iPTH and gland weight [4]. The aim of this study was to describe the relationship between parathyroid hormone and parathyroid adenoma volume, in patients with parathyroid adenomas as predictive value.

\section{Methods}

The multicenteric study was prepared by retrospectively collecting data from 244 patients with parathyroid adenoma who underwent parathyroidectomy and followed up between 2010 and 2020. The protocol of the study was revised and approved by the institutional committee and each patient was provided informed consent before participating in the study. All of the operations were 


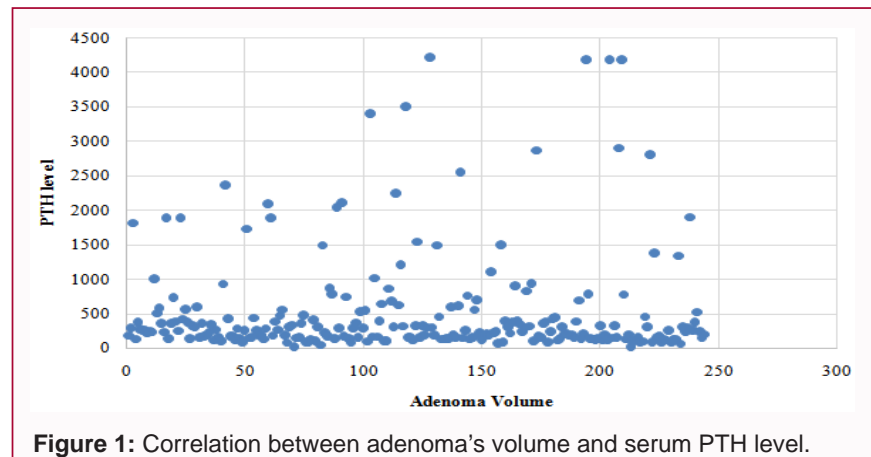

performed by two surgeons with the same experience. No relationship was seen between adenoma weight and age or sex of patients. Patients with parathyroid carcinoma, parathyroid hyperplasia, multiple adenomas, secondary or tertiary HPT, and those with serum creatinine more than $1.5 \mathrm{mg} / \mathrm{dl}$ were excluded. Preoperative and postoperative blood samples were taken from the patients and their PTH values were compared and the relation of these PTH values with the volume of parathyroid adenoma was evaluated. Parathyroid adenoma localization was tried to be determined radiologically before the operation. Correlation coefficients were calculated for surgically removed parathyroid adenoma volume with preoperative serum iPTH. The data collected by the research were processed by program package SPSS (version 20). Probability values of less than 0.05 were considered significant.

\section{Results}

Two hundred forty and four (female/male $=203 / 41$ ) patients with a mean age of 51.41 [min-max: 17 to 88 ] years were enrolled into the study. The mean iPTH concentrations preoperatively were $584.27 \mathrm{ng} / \mathrm{L}$ [min-max: 18.9 to $5011 \mathrm{ng} / \mathrm{L}$ ]. The mean diameter of adenoma of patients was $2,865 \mathrm{~mm}^{3}$ [min-max: 0.119 to $42.3 \mathrm{~mm}^{3}$ ]. After parathyroidectomy, PTH values were reevaluated and found as $47.2 \mathrm{ng} / \mathrm{L}$ [min-max: 0.2 to $903 \mathrm{ng} / \mathrm{L}$ ]. In the patients with large parathyroid adenoma volume, preoperative PTH hormone values were statistically significantly higher $(\mathrm{p}=0.001)$ (Figure 1$)$.

At the operation, parathyroid adenomectomy was performed in the mediastinum of 15 patients (6.1\%), the right upper pole of 11 patients (4.5\%), the right lower pole of 104 patients (42.6\%), the left upper pole of 15 patients $(6.1 \%)$, the left lower pole of 91 patients (37.3\%), and the multiple foci of 8 patients (3.3\%).

On ultrasound, the adenoma was not seen in 19 patients, while 46 of them did not describe the correct focus. In scintigraphy, 15 of the adenomas could not be described and 153 were involved. However, $20.9 \%$ of scintigraphic involvement did not describe the location correctly. In total, only 4 patients needed a gamma probe. All had no involvement in scintigraphy and ultrasound.

\section{Discussion}

Hyperparathyroidism is a common endocrine disorder with potential complications of the bone, renal, neurocognitive, and cardiovascular systems. Clinicopathological primary hyperparathyroidism includes the parathyroid gland adenoma ( $80 \%$ to $85 \%$ ), parathyroid gland hyperplasia (10\% to $15 \%$ ), and cancer $(<1 \%$ to $5 \%)$ [5]. Parathyroid glands react to the low calcium level in serum by releasing parathormone. The increased level of parathormone is maintained by hypocalcemia and leads to cell replication and increased gland mass [6]. Multiple studies have shown variable degrees of correlation between several preoperative serum chemistry levels and parathyroid adenoma size and weight. A recent retrospective study of 155 patients with parathyroid adenomas suggests that preoperative PTH levels may alert the surgeon to the likelihood of small or large parathyroid adenomas [6]. Stawicki noticed that higher diagnostic PTH levels were correlated with the removed glands with a larger mass and larger volume [8]. According to Fang et al. [9], a positive correlation was found between the size and weight of the parathyroid gland and PTH, in patients with secondary hyperparathyroidism, after surgery. A significant reduction of PTH values after surgery was proved [9]. That is, larger parathyroid glands secreted more PTH. In our study, parathyroid adenoma volumes were correlated with preoperative and postoperative parathyroid hormone levels. Therefore, a positive correlation was found between adenoma volume and preoperative PTH level.

There are several limitations to the study. Our research has proven the relationship between parathyroid gland size and parathyroid hormone value; however, to decide whether the parathyroid gland value can be the determinant of gland localization, the research needs to be done on more patients.

\section{Conclusion}

For a successful parathyroidectomy, the surgeon needs an exact localization and the number of parathyroid glands to be removed. One of the important factors for the surgical indication is, among others, the value of the parathyroid hormone. Our current study found a positive association between baseline iPTH levels and adenoma weight. These results suggest that serum iPTH level may be useful in predicting parathyroid adenoma volume.

\section{References}

1. Heath $\mathrm{H}^{\text {rd }}$, Hodgson SF, Kennedy MA. Primary hyperparathyroidism. Incidence, morbidity, and potential economic impact in a community. $\mathrm{N}$ Engl J Med. 1980;302(4):189-93.

2. Ruda JM, Hollenbeak CS, Stack BC Jr. A systematic review of the diagnosis and treatment of primary hyperparathyroidism from 1995-2003. Otolaryngol Head Neck Surg. 2005;132(3):359-72.

3. Randhawa PS, Mace AD, Nouraei SAR, Stearns MP. Primary hyperparathyroidism: Do perioperative biochemical variables correlate with parathyroid adenoma weight or volume? Clin Otolaryngol. 2007;32(3):179-84.

4. Saxe AW, Lincenberg S, Hamburger SW. Can the volume of abnormal parathyroid tissue be predicted by preoperative biochemical measurement? Surgery. 1987;102(5):840-5.

5. Duan K, Gomez Hernandez K, Mete O. Clinicopathological correlates of hyperparathyroidism. J Clin Pathol. 2015;68(10):771-87.

6. Michels TC, Kelly KM. Parathyroid disorders. Am Fam Physician. 2013;88(4):249257.

7. Mózes G, Curlee KJ, Rowland CM. The predictive value of laboratory findings in patients with primary hyperparathyroidism. J Am Coll Surg. 2002;194(2):126-30.

8. Stawicki SP, El Chaar M, Baillie DR, Jaik NP, Estrada FP. Correlations between biochemical testing, pathology findings, and preoperative sestamibi scans: A retrospective study of the Minimally Invasive Radioguided Parathyroidectomy (MIRP) approach. Nucl Med Rev Cent East Eur. 2007;10(2):82-6.

9. Fang L, Tang B, Hou D, Meng M, Xiong M, Yang J. Relationship between parathyroid mass and parathyroid hormone level in hemodialysis patients with secondary hyperparathyroidism. BMC Nephrology. 2015;16:82. 